\title{
Relation between nocturnal symptoms and changes in lung function on lying down in asthmatic children
}

\author{
A Greenough, L Everett, J Pool, J F Price
}

\begin{abstract}
Nocturnal symptoms are common in young asthmatic children. Such symptoms may be caused by increased impairment of lung function when they adopt the supine posture. Thirty one children aged $2 \cdot 8-8 \cdot 3$ years were studied, of whom 20 had asthma (10 with frequent nocturnal symptoms) and 11 had no respiratory problems (control subjects). Peak expiratory flow (PEF) was measured with a Wright's peak flow meter and functional residual capacity (FRC) by a helium gas dilution technique after 30 minutes of lying supine; the values were compared with FRC measured sitting and PEF standing. Peak flow fell significantly on adoption of the supine posture in the asthmatic children, but there was no difference in this fall between the asthmatic children with and without nocturnal symptoms. FRC also fell on adoption of the supine posture, but the decrease in FRC was significant only in the control children and the asthmatic children without nocturnal symptoms. The failure to find a greater fall in PEF or a greater change in FRC on adoption of the supine posture among asthmatic children with nocturnal symptoms suggests that mechanisms other than increased impairment of lung function are responsible for nocturnal asthma.
\end{abstract}

At least $70 \%$ of asthmatic children have attacks of coughing or wheezing at night. Several mechanisms have been postulated but nocturnal asthma is still not fully understood. On lying down healthy subjects have a small fall in peak expiratory flow $(\mathrm{PEF})^{1-3}$ and asthmatic subjects a greater fall. ${ }^{4}$ Coughing and wheezing do not develop as soon as the supine posture is adopted so this posture related fall in PEF is unlikely to be the sole explanation for nocturnal symptoms. It may, however, predispose to asthma occurring later in the night, when circulating levels of endogenous catecholamines and corticosteroids fall $^{56}$ and the circadian variation in airway calibre reaches its nadir. ${ }^{7-9}$ Although a much greater fall in PEF occurs in asthmatic than in non-asthmatic children, no previous studies have examined the relation between change in PEF on lying down and the presence of nocturnal symptoms.
Functional residual capacity (FRC) also falls when normal children lie down ${ }^{10-12}$ but the effect of posture on FRC has not been investigated in asthmatic children. In previous studies we found a close inverse correlation between PEF and FRC, increase in PEF being related to decrease in FRC. Thus if there is a clinically important fall in PEF on lying down an increase in FRC might be expected.

The aims of this study were to determine whether a reduction or a rise in FRC occurs in asthmatic children when they lie down, and whether asthmatic children with nocturnal symptoms show greater impairment of lung function, as judged by changes in PEF and FRC, when they adopt the supine position than asthmatic children who are symptom free at night.

\section{Methods}

PATIENTS

Thirty one children (20 boys, 11 girls) with a median age of 6.0 (range $2.8-8.3$ ) years were recruited. Twenty (median age $6 \cdot 5$, range $2 \cdot 8$ 8.3 years) were attending hospital for perennial asthma. The diagnosis of asthma was made on the basis of frequent episodes of coughing or wheezing or both and a change of at least $8 \%$ in FRC in response to a bronchodilator. ${ }^{14}$ All children were receiving beta adrenoceptor agonists; in addition, two were being treated with oral theophylline, two with sodium cromoglycate, and 12 with inhaled corticosteroids. Ten children (median age $6 \cdot 5$, range 3.8-8 years) gave a history of nocturnal cough or wheezing at least three nights a week in the period before the study; the other 10 (median age $6 \cdot 6$, range $2 \cdot 8-8 \cdot 3$ years) had no persistent nocturnal symptoms. The other 11 children (median age $5 \cdot 8$, range $4 \cdot 1-8.0$ years) were recruited from a local school. All were healthy and had no respiratory problems. These 11 children acted as control subjects.

Permission for this study was granted by the King's College Hospital ethics committee and informed parental consent was also obtained.

\section{INVESTIGATIONS}

The children were studied in the paediatric respiratory laboratory between 8 and $10 \mathrm{am}$. They omitted their beta adrenoceptor agonists for at least six hours before attending the laboratory but continued their other treatment as usual. PEF was measured in the standing position and FRC while they were sitting. Each
Address for reprint requests: Dr Greenough

Accepted 20 October 1990 


\section{FRC}

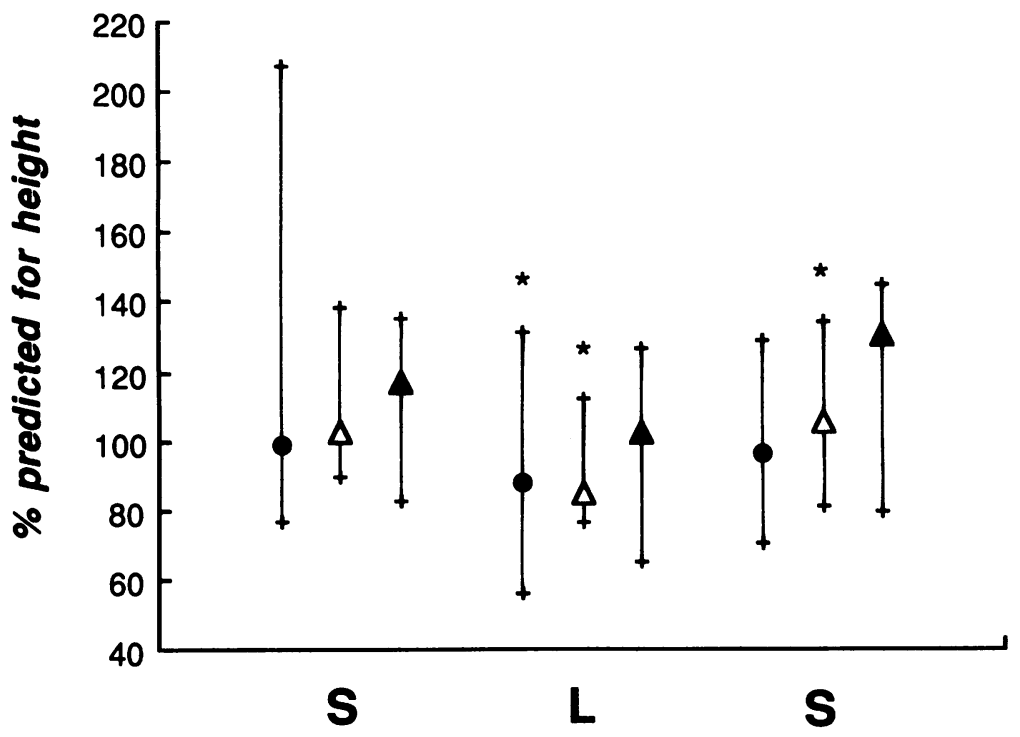

Figure 1 Change in functional residual capacity (FRC) in response to changes of posture in control $(O)$, symptomless $(\triangle)$, and symptomatic $(\Delta)$ children. $S-$ sitting; $L-$ lying. Significant changes $\left({ }^{\star} p<0.05\right)$ in FRC occurred on lying supine in control children and on lying down and then on sitting up again in the symptomless asthmatic children.

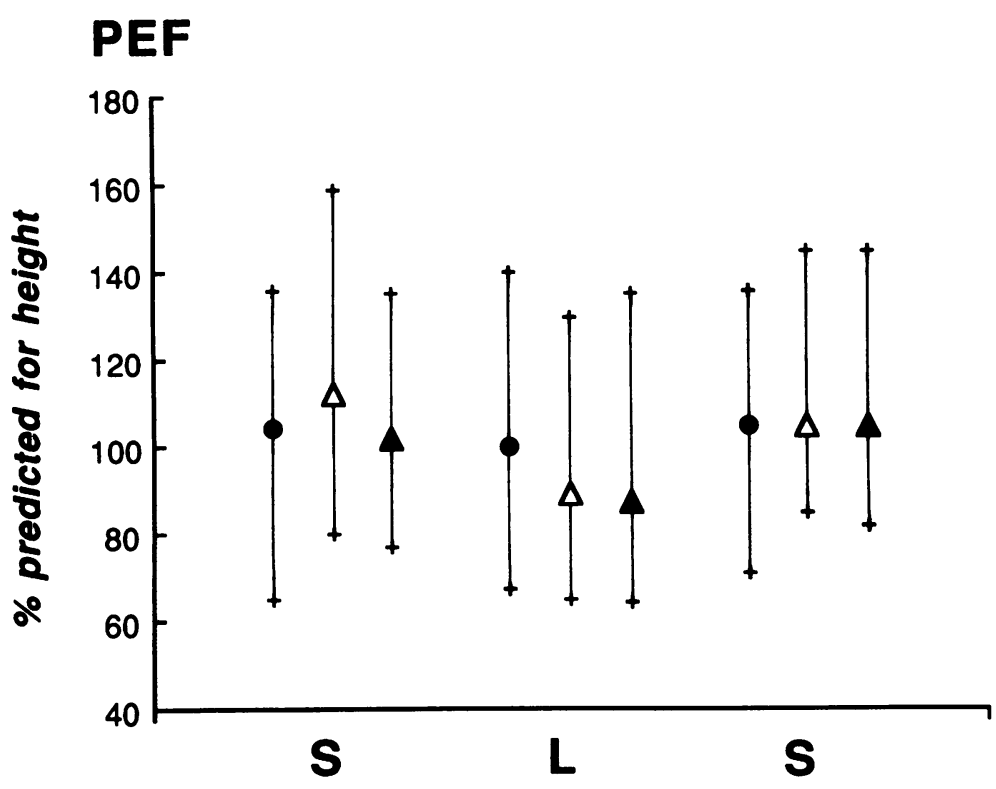

Figure 2 Change in peak expiratory flow (PEF) in response to changes of posture in control ( ), symptomless ( $\triangle$ ), and symptomatic ( $\Delta$ ) children. S-standing; $L$ lying. are incorporated into the spirometer, which has a total volume of 6 litres. The accuracy of the spirometer was checked daily with a calibrated syringe (Vitalograph, Buckingham). FRC was displayed by a continuous digital readout and recorded every 15 seconds; equilibration was assumed when the display showed a change of less than $20 \mathrm{ml}$ over 30 seconds. Recordings of FRC were coded and subsequently analysed without access to clinical information. Results of both measurements were expressed as percentages of those predicted for height, on the basis of our normal ranges for $\mathrm{FRC}^{15}$ and those of Murray et al for PEF. ${ }^{16}$ The mean coefficient of variation for measurement of FRC in young asthmatic children was $4 \%$ in our previous study. ${ }^{15} \mathrm{We}$ therefore considered a decrease in FRC on lying down or an increase on returning to the vertical position of at least $8 \%$ of the value predicted on the basis of height to be a posture related change. We had previously found the coefficient of variation for the measurement of PEF in young asthmatic children to be $8.8 \%$; thus a posture related change in PEF was designated as greater than $18 \%$ of the value predicted for height. ${ }^{17}$

SIZE OF TRIAL

Recruitment of 10 patients to each asthmatic group gave the study $80 \%$ power at the $5 \%$ level to detect a difference in FRC of $15 \%$ (in the $\%$ predicted for height values) between the two groups when they adopted the supine posture.

\section{STATISTICAL ANALYSIS}

Differences in PEF and FRC between the three groups of children and between the lying and the sitting position were assessed for statistical significance with a Wilcoxon rank sum test. The number of children showing a posture related change in PEF and FRC in each group was compared by means of Fisher's exact test.

\section{Results}

Asthmatic children, particularly those with nocturnal symptoms, tended to have a lower PEF and a higher FRC in both the upright and the supine posture (figs 1 and 2); the differences between the groups were not, however, statistically significant.

There was no significant difference in standing PEF measurements before and after lying down in any of the three groups. In most children the change in PEF on lying down was less than $18 \%$ of that predicted for height (table). In the control subjects the fall in PEF on lying down was not statistically significant (median (range) $104 \%(65-136 \%$ ) standing, $100 \%(67-140 \%)$ lying). PEF returned to baseline values when they stood up again. When the 20 asthmatic children changed from standing to lying PEF fell significantly $(110 \%$ $(77 \%-159 \%)$ standing, $89 \% \quad(65 \%-136 \%)$ lying; $p<0.05)$. The change in PEF on adoption of the supine posture did not differ significantly between the symptomless and the symptomatic asthmatic children $(102 \%$ (77$135 \%)$ standing, $89 \%(65-130 \%)$ lying in spirometer (Gould Pulmonet 3). The face mask has a semi inflated diaphragm at its edge to improve the seal and it was held firmly in position to prevent leaks. An internal carbon dioxide absorber and adjustable oxygen supply

child then lay in the supine position on a bare (standing) and FRC (sitting) were made minutes later.

Peak flow rate was measured with a low occasion. FRC was measured by helium gas dilution. ${ }^{15}$ The children breathed through a 
Number of children showing a posture related change in functional residual capacity (FRC) and peak expiratory flow (PEF) on lying supine

\begin{tabular}{llll}
\hline & Asthmatic & & \\
\cline { 2 - 4 } Change in & $\begin{array}{l}\text { Symptomatic } \\
(n=10)\end{array}$ & $\begin{array}{l}\text { Symptomless } \\
(n=10)\end{array}$ & $\begin{array}{l}\text { Control } \\
(n=11)\end{array}$ \\
\hline FRC $(>8 \%)$ & 9 & 8 & 8 \\
PEF $(>18 \%)$ & 1 & 3 & 2 \\
\hline
\end{tabular}

symptomless asthmatic subjects; $112 \%$ (80$159 \%)$ standing, $96 \%(80-136 \%)$ lying in symptomatic subjects.

Sitting FRC was similar before and after lying supine in all three groups. Most of the children in all three groups showed a change in FRC greater than $8 \%$ of the predicted value (table), when adopting the supine position. FRC fell significantly when they changed from sitting to lying supine both in the control children (median (range) $99 \%$ (71-208\%) sitting $88 \%(56-132 \%)$ lying; $p<0.05)$ and in the asthmatic children (110\% $(83-139 \%)$ sitting, 96\% (65-127\%) lying; $p<0.05)$. In the symptomless asthmatic children the changes in FRC were significant, both on lying supine $(85 \%, 77-113 \%)$ from sitting $(103 \%$, $90-139 \%)(p<0.05)$ and on resuming the sitting position $(\mathrm{p}<0.05)$; in the symptomatic asthmatic children the change in FRC when they lay supine was not significant $(103 \%$ (65\%-127\%) lying, $117 \%$ (83-136\%) sitting). The changes in FRC when they lay down did not differ significantly in asthmatic children with and without nocturnal symptoms.

\section{Discussion}

There is a circadian variation in airway calibre. In those without asthma the amplitude of change in PEF was $8.3 \%$ in one study, the airways being at their narrowest in the early morning. ${ }^{18}$ Asthmatic subjects show the same circadian rhythm but the amplitude is greater (51\% change in PEF in one series of adults ${ }^{9}$ and $22 \%$ in a group of children ${ }^{19}$ ). Reduction in airway calibre during the night could in part be related to adopting the supine posture. ${ }^{4}$ Our results confirm that peak flow falls on lying down. This change is directly related to the change in posture as in both this study and that of Haffajee et $a l^{4}$ peak flow recovered immediately after the subjects sat up. We also found that the reduction in peak flow when they lay down was greater in asthmatic children than in the healthy controls, in keeping with the differences in amplitude of circadian rhythm found between asthmatic and control subjects.

We found a reduction in FRC in the supine posture in all three groups of children. This change may be due to a decrease in dynamic compliance of the lungs ${ }^{2}$ as a result of increased pulmonary blood flow and closure of small airways. Gravitational forces may also cause the diaphragm to move upwards because of increased abdominal pressure in the horizontal position. ${ }^{7}$ This effect might be expected to be less in individuals with asthma, who frequently have hyperinflated lungs even when their asthma is well controlled. ${ }^{20}$ The change in FRC when they lay down was, however, similar in asthmatic and control children in the present study.

Geubelle and Goffin ${ }^{10}$ reported a $9 \cdot 4 \%$ reduction in FRC in young children when they changed from the sitting to the supine posture; Taussig et $a l^{11}$ and Bar-Yishay et al ${ }^{12}$ have suggested that in healthy children this change may be as large as $27 \%$. In the latter study, however, the results were compared with values for sitting children of the same height predicted from the reference values of Polgar and Promadhat. ${ }^{21}$ In our study we compared values from the same child sitting and lying and found a posture related reduction in FRC on adoption of the supine posture in eight of the 11 children. The median change in FRC of $11 \%$ on changing posture is similar to that reported by Geubelle et al..$^{10}$

The reduction in peak flow in the supine posture was greater in the asthmatic children than in the healthy control children. This difference was not, however, related specifically to the presence of nocturnal symptoms, there being no difference between the magnitude of fall in peak flow and FRC on adoption of the supine posture between the asthmatic children with and without nocturnal symptoms. Our results suggest that mechanisms other than postural changes in lung mechanics are responsible for nocturnal symptoms. The children with nocturnal symptoms had the highest FRC and the lowest peak flow values regardless of posture. Hyperinflation, indicating air trapping, has previously been shown to correlate with poor control of asthma ${ }^{20}$ and increased severity of disease. ${ }^{14}$ Nocturnal symptoms probably reflect poor asthma control or a greater degree of irreversible airflow obstruction.

Financial support for Sister Lucy Everett and Sister Jeni Pool was from Children Nationwide and Sechrist Industries. We are grateful for secretarial assistance to Ms Sue Williams.

1 Moreno F, Lyons HA. Effect of body posture on lung volumes. J Appl Physiol 1961;16:27-9.

2 Behrakis PK, Baydur A, Jaegar M, Milic-Emili J. Lung mechanics in sitting and horizontal body positions. Chest 1983;82:643-6.

3 Hetzel MR, Clark TJM. Does sleep cause nocturnal asthma? Thorax 1979;34:749-54.

4 Haffejee IE. Effect of supine posture on peak expiratory flow rates in asthma. Arch Dis Child 1988;63:127-9.

5 Barnes P, Fitzgerald G, Brown M, Dollery C. Nocturna asthma and changes in circulating epinephrine, histamine and cortisol. N Engl J Med 1980;303:263-7.

6 Pincus G. A diurnal rhythm in the excretion of certain urinary ketosteroids by young men. J Clin Endocrinol 1943;3:195-9.

7 Turner-Warwick $M$. On observing patterns of airflow obstruction in chronic asthma. Br JDis Chest 1977;71:73-85.

8 Reinberg A, Gervais P. Circadian rhythms in respiratory functions with special reference to human chronophysiology and chronopharmacology. Bull Physiopathol Respir 1972;8:663-77.

9 Hetzel MR, Clark TJH, Brown D. Normal circadian rhythms in peak expiratory flow rate [abstract]. Thorax 1978;33:668.

10 Geubelle F, Goffin C. Respiratory studies in children IV. Lung volumes and body positions in healthy children. Acta Paediatr 1962;51:255-60. 
11 Taussig LM, Harris TR, Lebowitz MD. Lung function in infants and young children. Am Rev Respir Dis 1977; 116:233-9.

12 Bar-Yishay E, Shulman DL, Beardsmore CS, Godfrey S Functional residual capacity in healthy preschool children lying supine. Am Rev Respir Dis 1987;135:954-6.

13 Greenough A, Pool J, Price JF. Changes in functiona residual capacity in response to bronchodilator therapy among young asthmatic children. Pediatr Pulmonol 1989;7:8-11.

14 Greenough A, Pool J, Loftus G, Price JF. Abnormalities of lung mechanics in young asthmatic children. Thorax 1987;42:500-5.

15 Greenough A, Stocks J, Nothen U, Helms P. Total respiratory compliance and functional residual capacity in young children. Pediatr Pulmonol 1986;2:321-6.
16 Murray AB, Cook CD. Measurement of peak flow expiratory flow rates in 220 normal children from $4 \cdot 5-18.5$ years of age. J Pediatr 1963;62:186-92.

17 Greenough A, Everett L, Price JF. Are we recording peak flows properly? Eur Respir $J$ (in press).

18 Hetzel MR, Clark TJH. Comparison of normal and asthmatic circadian rhythms in peak expiratory flow rate. Thorax 1989;35:732-8.

19 Sly PD, Hibbert ME, Landau CI. Diurnal variation of peak expiratory flow rate in asthmatic children. Pediat Pulmonol 1986;2:141-6.

20 Pool JB, Greenough A, Price JF. Abnormalities of functional residual capacity in symptomatic and asymptomatic youn asthmatics. Acta Paediatr Scand 1988;77:419-23.

21 Polgar G. Promadhat V. Pulmonary function testing in children. Philadelphia: Saunders, 1971:109. 